УДК 81.42

DOI 10.18413/2712-7451-2020-39-1-119-129

\title{
КОГНИТИВНЫЕ ОСНОВАНИЯ ИНТЕРАКЦИИ В МАРКЕТИНГОВОМ ДИСКУРСЕ
}

\author{
COGNITIVE BASES OF INTERACTION \\ IN A MARKETING DISCOURSE
}

\author{
Д.А. Черемохина, И.М. Чеботарева \\ D.A. Cheremokhina, I.M. Chebotareva
}

Белгородский государственный национальный исследовательский университет, Россия, 208015, г. Белгород, ул. Победы, 85

Belgorod National Research University, 85 Pobeda St, Belgorod, 308015, Russia

E-mail: Cheremohina@bsu.edu.ru; Ichebotareva@bsu.edu.ru

\begin{abstract}
Аннотация
Знаковым коммуникативным феноменом современности является маркетинговый дискурс, образование и функционирование которого слабо изучены в современной лингвистике. Важным вопросом этой области знания является определение роли когнитивных факторов дискурсопорождения в сфере продаж услуг. Авторами представлена попытка описания специфики коммуникативной ситуации в условиях деловых переговоров, а также обозначены лингвокогнитивные факторы формирования маркетингового дискурса (в частности, дискурса продажи услуг). Возможность проведения деловых переговоров, по мнению авторов, обусловлена наличием общих смыслов в когнитивной базе клиента и представителя компании. Концептуальный анализ ключевого для маркетингового дискурса концепта «выгода» позволил выявить точки пересечения интересов адресата и адресанта. Успех сделки становится возможным, если базовые индивидуальные смыслы концепта совпадают у обоих коммуникантов. Однако нередко в области персонального у коммуникантов реализуются смыслы с противоположным значением, что обусловлено личным опытом или этнокультурной спецификой. В таком случае представитель институционального дискурса стремиться трансформировать ядро концепта «выгода», используя при этом аргументацию и лингвистические средства языкового манипулирования. Результатом исследования стала схема, отражающая механизмы образования дискурса продаж, а также теоретические выводы о значимости традиционных для русской культуры («польза», «материальный интерес» и др.) и коммуникативно обусловленных ситуацией переговоров (например, «простая схема») смыслов.
\end{abstract}

\begin{abstract}
Changes in the economic situation in society have influenced the features of the functioning of the language. A special type of thinking is being formed - marketing. On the example of communication in the conditions of business negotiations, the features of verbalization of marketing thinking are considered. The process of discourse formation in the field of business negotiations is analyzed. The communicative area in which the interests of a company representative and a client intersect is defined as a sales discourse. The possibility of conducting business negotiations is due to the presence of common meanings in the cognitive base of the client and company representative. A conceptual analysis of the «Profit» concept, which is crucial for marketing discourse, made it possible to identify the «intersection points» of interests of the communicants. The success of the transaction becomes possible if the nuclear meanings of this concept are the same for both communicants. However, much more often in the nuclear part of the concept, represented in the client's speech, meanings with a negative value appear due to personal experience or ethnocultural specifics. In this case, the representative of the institutional strive to transform the core of the concept of «Benefit», using argumentation and linguistic means of language manipulation.
\end{abstract}


Ключевые слова: маркетинговый дискурс, дискурс продаж, дискурсообразование, концепт, концептуальный смысл, когнитивная трансформация.

Keywords: marketing discourse, sales discourse, discourse formation, concept, conceptual meaning, cognitive transformation.

\section{Введение}

В центре современного научного познания находится человек: исследователей интересует, как в языке проявляется его личность, как он выражает свои интересы, цели и желания. Ответы на эти вопросы имеют и практическую ценность: зная механизмы речепорождения и речевосприятия, мы можем спланировать идеальный коммуникативный акт для достижения прагматического эффекта. Для исследования акта коммуникации принято пользоваться термином дискурс. Т.А. Ван Дейк отмечал: «Понятие дискурса так же расплывчато, как понятия языка, общества, идеологии. Мы знаем, что зачастую наиболее расплывчатые и с трудом поддающиеся определению понятия становятся наиболее популярными. "Дискурс" - одно из них» [Teun Van Dijk, 1998, p. 46].

Преимущества дискурсивного анализа в условиях формирования антропоцентрического подхода были обозначены еще в середине 50-х годов XX века в работе 3. Харриса [Harris, 1952]. Представители американской лингвистической школы и сегодня активно применяют этот метод для анализа языковых явлений разной природы [Langacker, 2008; Chafe, 2015; Givon, 2017]. Утвердился термин дискурс и в отечественной науке о языке. Динамический характер дискурса позволил ему органично вписаться в традиционную оппозицию «язык - речь», которая в новых антропоцентрических исследованиях предстала как «язык - дискурс - речь». В нашей работе под дискурсом понимается динамическое образование, репрезентирующее коммуникативное действие, а также вербально закрепленный результат этого действия.

Подробно исследовал дискурс и описал его типологические характеристики В.И. Карасик. В работе «О типах дискурса» он выделял два типа - персональный (личностно-ориентированный) и институциональный (статусно-ориентированный): «В первом случае говорящий выступает как личность во всем богатстве своего внутреннего мира, во втором случае - как представитель определенного социального института» [Карасик, 2000, с. 6]. Каждый из типов дискурса имеет свои разновидности, отличающиеся лексическими средствами, степенью субъективности участников, а также целью коммуникативного акта. К персональному дискурсу исследователь относит бытовое и бытийное общение, в котором личность реализует свой речетворческий потенциал, удовлетворяет потребность в коммуникации. В институциональном типе дискурса речетворчество индивида ограничивается его социально-ролевым статусом.

В коммуникативной среде условно можно выделить политический, дипломатический, юридический, педагогический, религиозный, медицинский, деловой, научный типы дискурсов. Этот список может меняться под воздействием экстралингвистических факторов: в каждом типе может быть выделена собственная разновидность дискурса с присущим только ему набором лексических, грамматических и стилистических особенностей, а также прагматических установок. Кроме того, социальные институты исторически изменчивы, они меняют свои функции, расширяют коммуникативные границы (например, некоторые ведомства создают виртуальные дискурсы, в которых размещают важную информацию, отвечают на вопросы и т.д.).

Знаковым для нашего времени является формирование и активное функционирование маркетингового дискурса, разновидностью которого является дискурс продаж. Подъем предпринимательской активности в сфере продажи услуг, по замечанию А.П. Репьева, требует формирования особого типа мышления - маркетингового: «Маркетинговое мышление - это не мышление в чистом виде, а сочетание умения мыслить и чувствовать "помаркетинговому" с умением принимать творческие решения» [Репьев, 2015, с. 58]. Этот 
особый тип мышления, на наш взгляд, является когнитивной основой маркетингового дискурса, в котором прагматика современности реализуется в сочетании творческого и схематичного, личного и общественного.

Объектом нашего исследования и выступает этот тип дискурса - маркетинговый. В исследовательской литературе можно встретить несколько терминологических вариантов этого дискурса: маркетинговый дискурс [Гусейнова, 2009], дискурс маркетинговых коммуникаций [Пирогова, 2011], дискурс предметной области «Маркетинг» [Петрушова, 2011]. Следует отметить, что в нашей статье мы используем термин маркетинговый дис$к у р c$ в узком значении, понимая его как последовательность речевых интеракций, определяемых требованиями ситуации деловых переговоров. Мы говорим о дискурсе продаж страховых услуг, который формируется в процессе деловых переговоров с потенциальным покупателем при учете экстралингвистических факторов. Таким образом, предметом нашего исследования выступает речевое поведение коммуникантов в типовой ситуации деловых переговоров.

Актуальность исследования определяется необходимостью изучить особенности дискурсопорождения в сфере продаж услуг и определить роль когнитивных факторов в этом процессе. Нас интересует, как в новых экономических условиях функционирует язык, как меняется языковое сознание участников коммуникации и как формируется маркетинговый дискурс. Цель исследования - определить лингвокогнитивные факторы формирования маркетингового дискурса (в частности, дискурса продажи услуг) и обозначить специфику коммуникативной ситуации в условиях деловых переговоров.

Гипотезой исследования выступает предположение о том, что порождение дискурса продаж как разновидности маркетингового дискурса определяется столкновением и взаимодействием институционального и персонального в жанре деловых переговоров, которые рассматриваются нами как интеракция с особой маркетинговой прагматикой. Мы считаем, что существование дискурса продаж как типовой формы маркетингового дискурса обусловлено когнитивными факторами, имеющими этнокультурные и общеязыковые истоки.

\section{Материалы и методы исследования}

Материалом исследования явились письменные результаты работы на тренингах, которые проводились компанией «Дженсер», являвшейся до 2018 года лидером по продажам автомобилей и услуг, связанных с допродажным и сервисным обслуживанием (в том числе, страхованием автомобилей). Анализируемые в статье фрагменты дискурса продаж разработаны автором по коммуникативным ситуациям, представленным в заданиях тренингов «Особенности работы с продуктом. Продажа услуг» (август 2013, г. Белгород) и «Активные продажи услуг в автоцентре» (апрель 2014, г. Белгород).

Особенности материала исследования определили методологическую основу работы. Одним из ведущих методов является метод концептуального анализа, основанный на выделении доминирующего концепта, который, с одной стороны, обусловливает наличие «точек контакта» коммуникантов, а с другой - столкновение интересов участников переговоров. Многие общие выводы и положения в нашей работе сформированы благодаря анализу частных лингвистических проявлений, что составляет суть метода индуктивного анализа. Важен для достижения цели нашего исследования и сопоставительноописательный метод, позволяющий провести сравнение по различным показателям речевого поведения коммуникантов.

\section{Результаты и их обсуждение}

Дискурс продаж услуг (как разновидность маркетингового дискурса) образуется при участии двух сторон: клиента (покупателя) и представителя компании (продавца услуги). Коммуникация проходит в жанре деловых переговоров, которые представляют собой интеракцию покупателя и продавца. Клиентом в данном случае создается область 
бытового дискурса, ему, например, нужно застраховать свой автомобиль, потому что истекает срок действия полиса. Покупатель услуги может использовать тот набор языковых средств, который, на его взгляд, оптимально подходит для решения этой практической задачи. Выбор способов репрезентации своих потребностей определяется и набором экстралингвистических факторов: образованием, настроением, прошлым опытом. Продавец, наоборот, ограничен в способах репрезентации информации. В ситуации деловых переговоров он выступает представителем компании и должен соответствовать ее имиджу. Таким образом, коммуникативная область, создаваемая продавцом, соответствует институциональному типу дискурса. Представим эту идею схематично (см. рисунок):

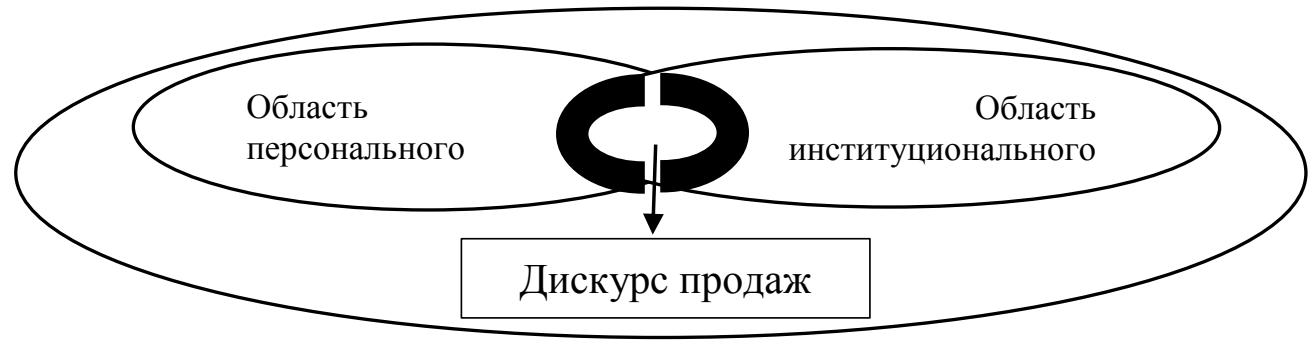

Дискурсообразование в жанре деловых переговоров Discourse formation in the genre of business negotiations

Все рассматриваемые в нашей статье примеры деловых переговоров являются результатами работы на тренинге. Следует отметить, что тренинг - это «система тренировок для совершенствования в какой-либо сфере жизни, для снятия отрицательных воздействий и т.п.» [Скляревская, 2007, с. 999]. В основе тренингов по продажам услуг лежат теоретические знания по психологии и психолингвистике, а также набор практических заданий, позволяющих закрепить полученную информацию. Нас интересует результаты работы на тренинге, то есть тексты «идеальных» с точки зрения маркетинга диалогов.

Рассмотрим следующий пример:

- Мне кажется, что ваша страховка - вещь абсолютно бесполезная! Я и так все деньги вкладываю в машину, а вы еще из меня их на всякие глупости вытягиваете!

- Приобретение автомобиля - действительно важное дело. Хотите понять, в чем польза страхования для вас и вашей семьи?

Обратим внимание на лингвистические средства выражения позиций покупателя и продавца.

\section{Позиция покупателя}

- Лексика с отрицательной оценкой (бесполезная, глупости);

- Стилистически окрашенная лексика (вытягивать деньги - разговорный стиль);

- Противительные конструкции (Я $u$ так..., a вbl..);

- Усилительная частица (абсолютно);

- Восклицательные предложения.

Вывод: перед нами «живая», неподготовленная речь, выражающая нежелание приобретать услугу. Языковые средства оформления соответствуют разговорному стилю речи. Это область персонального дискурса.

\section{Позиция продавца}

- Лексика с положительной оценкой (важное, польза);

- Канцеляризм (приобретение автомобиля);

- Закрытий вопрос с указанием ценности для клиента и его семьи;

- Прием парафраза, демонстрирующий лояльность и согласие с позицией клиента.

Вывод: перед нами речь, построенная по схеме «понять природу сомнений нейтрализовать эмоцию недоверия (согласиться) - проговорить желание (парафраз)». Языковые средства соответствуют официально-деловому стилю. Это область институционального дискурса 
Приведенный пример доказывает, что клиент может использовать языковые средства разных уровней и оформлять высказывание, используя стилистически окрашенные элементы, в то время как для сотрудника такое речевое поведение недопустимо: придерживаясь социального статуса представителя компании, он должен тщательно выбирать лингвистический арсенал для формирования лояльности клиента. Итак, маркетинговый дискурс формируется при взаимодействии и столкновении институционального и персонального в жанре деловых переговоров.

Мы говорим о двух противоположных процессах взаимодействия и столкновения (оппозиции) потому, что не всегда интеракция протекает так, как это предполагается «идеальной» схемой, описанной в тренинге. Рассмотрим когнитивные причины возможных столкновений.

Необходимым средством общения является речь, которая в концепции когнитивной лингвистики представляет собой высший уровень категоризации и концептуализации информации. Именно в речи репрезентирован весь ментальный комплекс знаний и представлений человека, который в терминосистеме когнитивной лингвистики называется концептосферой, а «квант» этого знания - концептом. Чумак-Жунь И.И. вслед за Е.С. Кубряковой утверждает, что концепт - это «оперативная содержательная единица памяти, ментального лексикона, концептуальной системы и языка мозга, а также всей картины мира, отраженной в человеческой психике» [Чумак-Жунь, 2009, с. 12]. Возможно ли трансформировать те или иные концептуальные смыслы для достижения нужного прагматического эффекта? Считаем, что такие трансформации возможны, и объясняются они спецификой формирования самого концепта. «При формировании концепта в человеческом сознании происходит синкретичное соединение двух сущностных основ: с одной стороны, это 1) культурные архетипы социума, в котором существует индивид (когнитивная база), а с другой, это 2) его индивидуальное сознание» [Черемохина, 2015, с. 46]. Для достижения практической цели коммуникации представитель компании (адресант области институционального дискурса) должен «подключиться» к когнитивной базе адресата, выявить возможные негативные смыслы ключевого концепта и трансформировать их. На наш взгляд, ключевым концептом, который обеспечивает интеракцию на пересечении областей институционального и персонального в дискурсе продаж, является концепт «Выгода».

В «Толковом словаре русского языка» под редакцией Д.Н. Ушакова лексема «выгода» трактуется следующим образом: «ВЫГОДА, ж. Прибыль, польза, извлекаемая из чего-н., преимущество, интерес (чаще материальный). Коллективное хозяйство дает много выгод. Нет никакой выгоды покупать дешевую одежду. Это не в моих выгодах (мне невыгодно). Иметь, получать выгоду» ${ }^{1}$. Похожее толкование находим и в Малом толковом словаре русского языка: «ВЫГОДА, -ы, ж. Польза, преимущество; Прибыль. Это дело вряд ли даст выгоду. Думать о собственной выгоде. Поменяться с выгодой для себя» ${ }^{2}$ Опираясь на данные толковых словарей, выделяем концептуальные смыслы исследуемого концепта: «польза», «материальный интерес».

Следует отметить, что понимание выгоды как индивидуальной прибыли, личного интереса сформировалось в недрах русского национального сознания и имеет древние истоки. Вспомним русские пословицы «Своя рубашка ближе к телу», «Своя рука - владыка ${ }^{3}$, в которых отражена черта русского человека, часто ставящего собственное благополучие выше интересов других людей. Конечно, есть в русской истории и периоды отрицания индивидуализма, периоды признания ценности коллективизма и стремления к общей

${ }^{1}$ Ушаков Д.С. 2005. Большой толковый словарь современного русского языка. М., АльтаПреcc, c. 114

2 Лопатин В.В., Лопатина Л.Е. 1990. Малый толковый словарь русского языка: Ок. 35000 слов. М., Русский язык, с. 74.

${ }^{3}$ Русские пословицы и поговорки. 1988. М., Художественная литература, с. 281 
возвышенной цели. Тем не менее, сегодня, под натиском рыночной экономики и конкуренции, одним из когнитивных факторов организации деловых переговоров в маркетинговом дискурсе является актуализация традиционного для русского менталитета смысла «личный интерес».

Народная мудрость выражает еще одну важную мысль, которая часто лежит в основе сомнений и возражений в ситуации деловых переговоров: «Выигрыш с проигрышем на одних санях ездят» ${ }^{1}$, «Не гонись за большим - маленькое потеряешь» ${ }^{2}$ и т.д. Современное: «Если это предложение действительно такое выгодное, то почему Вы мне его предлагаете? Наверное, это уловка!», - типичное для русского человека восприятие информации о выгодных предложениях. Таким образом, добавим еще несколько возможных концептуальных смыслов анализируемого концепта - это смыслы «обман» и «скрытая цель».

Успешная интеракция в дискурсе продаж определяется совпадением положения концептуальных смыслов в структуре основного концепта. Рассмотрим, какие смыслы репрезентируются в репликах из области персонального и какое положение в структуре концепта они занимают.

1) - Когда по телефону я с Вами разговаривала, иена была одной, а теперь вдруг выросла на пять тысяч. Ничего себе «стабильная» компания.

2) - Я машину четыре года страховал из-за кредита, сейчас погасил. ДТП не было, страховка мне больше не нужна.

3) - Мы переехали, у меня теперь гараж есть, страховка от угона больше не нужна. Зачем мне деньги выбрасывать?

4) - Я о вашей компании «ХХХ» такого в интернете начиталась! А вы мне ее предлагаете!

5) - Я сльшал, что при страховом случае страховые делают все, лишь бы не заплатить! Не вижу смысла страховаться!

6) - У моих знакомых был очень неприятный случай с этой страховой компанией! К ним я не хочу обрашаться!

7) - У меня 18 лет стажа, зачем мне еще дополнительная страховка?

8) - Вы все рассказываете, конечно, очень заманчиво, но я сильно сомневаюсь в том, что все это соответствует реальности.

9) - Эта система страховая очень сложная: я все равно не смогу воспользоваться ей! Куда-то звонить, договариваться. Я лучше в знакомый сервис поеду и быстро все сделаю, если что-то случится.

Основываясь на анализе приведенных примеров, считаем, что в приядерную часть концепта «выгода» попадают как традиционные для нашей этнокультуры, так и характерные только для этого типа дискурса концептуальные смыслы. К традиционным относим концептуальные смыслы: «материальный интерес» (пример 1 можно перефразировать следующим образом: «мне выгодно там, где дешевле»), «личный интерес» (примеры 2, 3, 7, в которых вербализируется мысль «лично мне выгодно жить без подобных услуг, потому что у меня нет перед вами обязательств, и я в себе уверен») и «обман» (в примерах 8 и 6 представлена мысль «выгода там, где нет скрытых смыслов, а им нужно только продать, поэтому меня обманут»). В примерах 5 и 9 обращаем внимание на новый концептуальный смысл, не отмеченный нами ранее, - «простая схема» (имеется в виду, что для клиента выгодно то предложение, реализация которого не потребует от него больших усилий).

Конечно, концептуальные смыслы репрезентируются не изолировано. Мы выделили лишь те, которые, на наш взгляд, в указанных примерах входят в приядерную часть

\footnotetext{
${ }^{1}$ Русские пословицы и поговорки. 1988. М., Художественная литература, с. 56

${ }^{2}$ Русские пословицы и поговорки. 1988. М., Художественная литература, с. 213
} 
концепта. В каждой из реплик вербализовано несколько концептуальных смыслов, например, в реплике 4 (Я о вашей компании «ХХХ》 такого в интернете начиталась! А вы мне еe предлагаете!) в ядро концепта, вероятно, попадут смыслы «обман» и «простая схема», а периферию составят смыслы «материальный интерес» (если обманут, то материальной выгоды тоже не будет) и «личный интерес» (обманут именно меня, это неприятно).

Концепт «выгода» (с указанными концептуальными смыслами) в области пересечения областей институционального и персонального подвергается направленному процессу трансформации, который изменяет представления клиента об услуге и формирует готовность приобрести ее.

1) - Когда по телефону я с Вами разговаривала, цена была одной, а теперь вдруг выросла на пять тысяч. Ничего себе «стабильная» компания.

- Действительно, вопрос финансовой стабильности страховой компании очень важен. Хотите узнать, почему изменилась цена?

В данном случае смысл «материальный интерес» в приядерной зоне концепта «выгода» находится рядом со смыслом «обман». Задачей представителя компании является формирование лояльности клиента, которое достигается с помощью закрытого вопроса и последующего объяснения причин подорожания. Возможно, что после уточнения некоторых фактов (дата звонка, страховая компания, личные данные водителей и т.д.), представления клиента о том, что его обманывают, сместятся на периферию концепта, а дополнительные персональные предложения специалиста компании сформируют новые концептуальные смыслы, такие как «личный интерес» («это предложение только для Вас») или «простая схема» («Вам близко к нам ехать»).

2) - Я машину четыре года страховал из-за кредита, сейчас погасил. ДТП не было, страховка мне больше не нужна.

- Очень хорошо, что есть опьт безаварийной езды! Хотите понять, какие дополнительные преимущества будут доступны для Вас как для опытного водителя?

«Личный интерес» клиента в данном примере заключается в отсутствии обязательств перед банком и, следовательно, перед страховой компанией. В дискурсе продаж актуализируется внимание на дополнительных преимуществах «только для вас», этот концептуальный смысл остается в приядерной зоне концепта, но насыщается новыми оттенками значения: у вас нет обязательств - значит у вас будет другой тариф по страхованию; вы опытный водитель - значит есть возможность получить дополнительную скидку; вы страховали свой автомобиль в нашей компании несколько лет - значит для вас доступны услуги для постоянных клиентов.

3) - Мы переехали, у меня теперь гараж есть, страховка от угона больше не нужна. Зачем мне деньги выбрасывать?

- Хорошо, что есть место для хранения автомобиля. Гараж, действительно, обеспечивает защиту от угона. Хотите узнать, какие дополнительные преимущества Вы получите от полиса КАСКО?

В основе реплики клиента лежит прием отрицания. Частица не (не нужна) и фразеологизм «выбросить деньги на ветер», представленный в области персонального усеченной разговорной формой «деньги выбросить», репрезентируют негативное отношение к предлагаемому продукту. Клиент уверен, что его личный интерес заключается в отсутствии дополнительных трат на ненужную услугу. Задача представителя компании в данном случает заключается в трансформации смыслового содержания этого концептуального смысла. Предположим, что в качестве аргументов для приобретения страховки адресант области институционального будет использовать предложения, обеспечивающие в себе материальную выгоду и формирующие уверенность в защите автомобиля не только от угона, но и от других страховых случаев (например, специальные продукты с франши- 
зой). Таким образом, концептуальный смысл «личный интерес» остается в приядерной зоне концепта «выгода», но, вероятно, в дискурсе продаж изменяет свое смысловое содержание.

4) - Я сльшал, что при страховом случае компании делают все, лишь бы не заплатить! Не вижу смысла страховаться!

- Понимаю, Вы хотите быть уверенным, что страховая компания выполнит свои обязательства! Рассказать о страховых компаниях, с которыми мы сотрудничаем?

Мнение о том, что добиться компенсации по страховому полису очень сложно, выражается и в следующем диалоге:

5) - Эта система страховая очень сложная: я все равно не смогу воспользоваться ей! Куда-то звонить, договариваться. Я лучше в знакомый сервис поеду и быстро все сделаю, если что-то случится.

- Действительно, важно понимать, как действовать в страховой ситуации. Хотите узнать, что нужно делать, чтобы быстро получить выплату и отремонтировать свой автомобиль у официального дилера?

Когнитивный диссонанс в области пересечения дискурсов возникает из-за несовпадения концептуального смысла «простая схема» области персонального и этого концептуального смысла в области институционального дискурса. Уверенность клиента в том, что даже после покупки страхового продукта он не сможет им воспользоваться, вербализируется на уровне лексики и грамматики: отрицательные частицы с усилением (не, лишь бы не, все равно не), прилагательное сложная.

Реплика клиента в диалоге № 6 построена на противопоставлении, которое актуализирует еще один оттенок значения смысла «простая схема»- выгодно, если быстро.

Представитель области институционального в данном случае соглашается с важностью «простой схемы» и дополняет приядерную зону концепта «выгода» новыми смыслами. Так, после аргументации страхового предложения (например, клиенту может быть предложена услуга «аварийный комиссар», которая позволит ему не ездить в страховую компанию и экономить время, решая все вопросы в салоне официального дилера) в приядерной зоне концепта, вероятно, появятся смыслы «удобное решение» или «надежная компания».

Рассмотрим еще один пример.

6) - Вы все рассказываете, конечно, очень заманчиво, но я сильно сомневаюсь в том, что все это соответствует реальности.

- Уверенность в страховой компании очень важна. Хотите узнать, какие гарантии выплат Bы получаете при приобретении страхового продукта?

Обращаем внимание, что реплики из области институционального дискурса построены по общей схеме и включают, в отличие от области персонального, положительно окрашенные языковые единицы, акцентирующие внимание на преимущества для клиента. Концептуальный смысл «обман» должен быть вытеснен на периферию концептуального поля смыслом или смыслами с положительным значением. Например, представитель компании может сформировать новое знание о страховой компании, оперируя фактами и примерами из своей практики. Кроме того, доверие клиента в этом случае формируется и с помощью экстралингвистических факторов: опрятный внешний вид, приятный голос и т.д. В результате деловых переговоров в приядерной зоне концепта «выгода» окажутся смыслы «простая схема» или «личный интерес».

Подведем итог. В процессе деловых переговоров формируется особое коммуникативное образование - дискурс продаж. Особенность этого типа дискурса заключается в том, что он совмещает в себе две противоположно заряженные области с разными когнитивными установками, но объеденные общей концептуальной зоной концепта «выгода». 
На пересечении областей институционального и персонального приядерные концептуальные смыслы подвергаются направленному процессу трансформации со стороны более сильного дискурса (таковым мы считаем дискурс, формируемый представителем компании, поскольку он относится к институциональному типу). Эта трансформация заключается в том, что концептуальные смыслы концепта «выгода», которые репрезентируются клиентом и выражают его негативное отношение к предлагаемому продукту, могут 1) смещаться на периферию (диалоги 1 и 6), тогда в приядерной зоне концепта оказывается другой концептуальный смысл с положительным значением; 2) оставаться в приядерной зоне концепта, но с новым оттенком значения, формирующим лояльность клиента (диалоги 2 и 3); 3) оставаться в приядерной зоне вместе с новыми концептуальными смыслами, под воздействием которых теряется отрицательное коннотативное и смысловое содержание концепта (диалоги 4 и 5).

Таким образом, традиционные представления о выгоде в маркетинговом дискурсе являются когнитивной основой интеракции. В области пересечения интересов институционального и персонального обязательно делается акцент на пользу для клиента. Для речевой манипуляции представителем компании выбираются важные для русского менталитета сферы влияния: семья, безопасность, финансовая стабильность, простота и скорость реализации сделки.

\section{Заключение}

Современная экономическая ситуация оказывает влияние на изменение картины мира человека, что, безусловно, отражается на особенностях функционирования языка. Маркетинговое мышление, которое сформировалось под воздействием рыночной экономики, определяет отбор языковых средств и уместность их использования в разных бытовых и официальных ситуациях, в том числе в ситуации деловых переговоров. Изучение лингвистических особенностей интеракции и механизмов дискурсообразования в ситуации деловых переговоров оказалось возможным при взаимодействии коммуникативного и когнитивного подходов к языковым фактам, которые являются результатами работы на тренингах и представляют собой образцовый текст, решающий маркетинговые задачи.

Типологические признаки маркетингового дискурса определяют уникальность этого коммуникативного образования. Адресат и адресант, становясь участниками переговоров, занимают разные социально-ролевые позиции: представитель компании использует средства официально-делового стиля, тщательно выбирая лингвистический арсенал для формирования лояльности клиента, который в свою очередь не ограничен в языковых средствах репрезентации своих потребностей и может оформлять высказывание, используя стилистически окрашенные элементы разговорного стиля. Интеракция в таком случае формируется путем взаимодействия и столкновения институционального и персонального в жанре деловых переговоров.

Коммуникативная область, в которой пересекаются интересы представителя компании и клиента, определяется нами как дискурс продаж. Возможность дискурсообразования обеспечивается наличием в сознании носителей языка общих концептуальных смыслов, объединенных в концепте «выгода». Исследование показало существование некоторых традиционных для русской культуры смыслов («польза», «материальный интерес» и др.), а также смыслов коммуникативно обусловленных ситуацией переговоров (например, «простая схема»). Представитель компании стремиться выявить индивидуальные представления о выгоде, репрезентированные в репликах клиента. «Неудобные» концептуальные смыслы подвергаются намеренному процессу трансформации и смещаются на периферию концептуальной области или, оставаясь в приядерной зоне, изменяют свое значение. 
Таким образом, считаем гипотезу исследования доказанной. Результаты исследования подтвердили, что порождение дискурса продаж определяется столкновением и взаимодействием институционального и персонального в жанре деловых переговоров, возможность осуществления которых обусловлена когнитивными факторами, имеющими этнокультурные и общеязыковые истоки.

\section{Список литературы}

1. Гусейнова И.А. 2009. О когнитивных основах маркетингового дискурса. В кн.: Бизнескоммуникация и языки для специальных целей: опыт, стратегии, проблемы. Материалы международной научно-практической конференции (Минск, 14-15 мая 2009 г.). Под ред.: В.С. Слепович. Минск, БГЭУ: 3-4.

2. Карасик В.И. 2000. О типах дискурса. В кн.: Карасик В.И., Слышкин Г.Г. Языковая личность: институциональный и персональный дискурс. Волгоград, Перемена: 5-6.

3. Петрушова Е.В. 2011. Когнитивно-прагматические характеристики дискурса предметной области «Маркетинг». Дисс. ... канд. филол. наук. Краснодар, 325 с.

4. Пирогова Ю.К. 2011. Феномен давления дискурса в текстах маркетинговых коммуникаций. В кн.: Язык и дискурс средств массовой информации в XXI веке. Под ред.: М.Н. Володиной. М., Академический проект: 208-217.

5. Репьев А.П. 2015. Маркетинговое мышление. М., Библос, 510 с.

6. Скляревская Г.Н. 2007. Толковый словарь русского языка начала XXI века. Актуальная лексика. М., Эксмо, 1136 с.

7. Черемохина Д.А. 2015. Когнитивно-прагматические факторы междискурсного конфликта (дискурс власти и дискурс В.С. Высоцкого). Дис. ... канд. филол. наук. Белгород, 170 с.

8. Чумак-Жунь И.И. 2009. Поэтический концепт и его статус в типологии концептов. Научные ведомости Белгородского государственного университета. Серия: Гуманитарные науки, 14: 11-20.

9. Chafe W.L. 2015. A Grammar of the Seneca Language. Oakland, California, University of California Press, XVI, 234 p.

10. Givon T. 2017. The Story of Zero, John Benjamins Publishing Company, 430 p.

11. Harris Z. 1952. Discourse Analysis. Language, 28 (1): 1-30.

12. Langacker R.W. 2008. Cognitive Grammar: A Basic Introduction Oxford, Oxford University Press, $562 \mathrm{p}$.

13. Teun Van Dijk. 1998. Ideology: A Multidisciplinary Approach. London, Sage. Available at: http://www.psyberlink.flogiston.ru/internet/bits/vandijk2.htm (accessed: 25.09.2019).

1. Guseynova I.A. 2009. O kognitivnykh osnovakh marketingovogo diskursa [On the Cognitive Basics of Marketing Discourse]. In: Biznes-kommunikatsiya i yazyki dlya spetsial'nykh tseley: opyt, strategii, problem [Business communication and languages for special purposes: experience, strategies, problems.]. Materialy mezhdunarodnoy nauchno-prakticheskoy konferentsii (Minsk, 14-15 maya 2009 g.). Ed.: V.S. Slepovich. Minsk, BGEU: 3-4.

2. Karasik V.I. 2000. O tipakh diskursa [About types of discourse]. In.: Karasik V.I., Slyshkin G.G. Yazykovaya lichnost': institutsional'nyy i personal'nyy diskurs [Language personality: institutional and personal discourse]. Volgograd, Peremena: 5-6.

3. Petrushova E.V. 2011. Kognitivno-pragmaticheskie kharakteristiki diskursa predmetnoy oblasti «Marketing» [Cognitive-pragmatic characteristics of the discourse «Marketing»]. Diss. ... cand. philol. sciences. Krasnodar, 325 p.

4. Pirogova Yu.K. 2011. Fenomen davleniya diskursa v tekstakh marketingovykh kommunikatsiy [The phenomenon of the pressure of discourse in the texts of marketing communications]. In.: Yazyk i diskurs sredstv massovoy informatsii v XXI veke [Language and Media Discourse in the 21st Century]. Pod red.: M.N. Volodinoy. M., Akademicheskiy proekt: 208-217.

5. Rep'ev A.P. 2015. Marketingovoe myshlenie [Marketing thinking]. M., Biblos, 510 p. 
6. Sklyarevskaya G.N. 2007. Tolkovyy slovar' russkogo yazyka nachala XXI veka. Aktual'naya leksika [Explanatory dictionary of the Russian language of the beginning of the XXI century. Actual vocabulary]. M., Eksmo, 1136 p.

7. Cheremokhina D.A. 2015. Kognitivno-pragmaticheskie faktory mezhdiskursnogo konflikta (diskurs vlasti i diskurs V.S. Vysotskogo) [Cognitive-pragmatic factors of inter-discourse conflict (power discourse and discourse of V.S. Vysotsky)]. Dis. ... cand. philol. sciences. Belgorod, $170 \mathrm{p}$.

8. Chumak-Zhun' I.I. 2009. Poeticheskiy kontsept i ego status v tipologii kontseptov [Poetic concept and its status in the typology of concepts]. Belgorod State University Scientific Bulletin. Humanities series, 14: 11-20.

9. Chafe W.L. 2015. A Grammar of the Seneca Language. Oakland, California, University of California Press, XVI, 234 p.

10. Givon T. 2017. The Story of Zero, John Benjamins Publishing Company, 430 p.

11. Harris Z. 1952. Discourse Analysis. Language, 28 (1): 1-30.

12. Langacker R.W. 2008. Cognitive Grammar: A Basic Introduction Oxford, Oxford University Press, $562 \mathrm{p}$.

13. Teun Van Dijk. 1998. Ideology: A Multidisciplinary Approach. London, Sage. Available at: http://www.psyberlink.flogiston.ru/internet/bits/vandijk2.htm (accessed: 25.09.2019).

\section{Ссылка для цитирования статьи For citation}

Черемохина Д.А., Чеботарева И.М. 2020. Когнитивные основания интеракции в маркетинговом дискурсе. Вопросы журналистики, педагогики, языкознания.. 39 (1): 119-129. DOI

10.18413/2712-7451-2020-39-1-119-129

Cheremokhina D.A., Chebotareva I.M. 2020. Cognitive bases of interaction in a marketing discourse. Issues in Journalism, Education, Linguistics, 39 (1): 119-129. (in Russian). DOI 10.18413/2712-

7451-2020-39-1-119-129 